\title{
ANALISIS GAMBAR HIASAN HIJAB
}

\author{
Fazri Bagas Prasojo ${ }^{1^{*}}$, Onggal Sihite ${ }^{2^{*}}$ \\ Program Studi Pendidikan Seni Rupa Jurusan Seni Rupa Fakultas Bahasa dan Seni \\ Universitas Negeri Medan \\ Jl. Willem Iskandar Pasar V Medan Estate, Kec, Percut Sei Tuan, Kab. Deli Serdang, Kode Pos 20371 \\ Sumatera Utara. Indonesia \\ Email:fazribagas@gmail.com
}

\begin{abstract}
Abstrak
Penelitian ini di latar belakangi untuk mengenalkan s alah satu media sederhana yang dapat digunakan sebagai media dalam pembuatan gambar hiasan pada hijab siswa kelas X SMK Karya Bunda. Pembatas an masalah dalam penelitian ini berfokus pada penerapan prinsip komposisi, keselarasan, irama, kes eimbangan dan tingkat keberhasilan pada pembuatan gambar hiasan di hijab siswa kelas $\mathrm{X}$ SMK Kary a Bunda. Tujuan penelitian iniadalah untuk mengetaui penerapan dan tingkat keberhasilan prinsip komposisi, kes elarasan, irama, dan keseimbangan pada pembuatan gambar hiasan di hijab siswa kelas X SMK Karya Bunda. Penelitian ini menggunakan metode kualitatif dengan sampel 5 karya gambar hiasan pada hijab siswa kelas X SMK Kary a Bunda yang diambil menggunakn teknik Sampling Purposive. Teknik analis is data dilakukan dengan teknik analis is deskriptif kualitatif. Berdasarkan data y ang telah diperoleh, maka semua hasil penilaian dari ke tiga ahli secara keseluruhan pada karya gambar hiasan padahijab siswa kelas X SMK Karya Bunda ditinjau berdasarkan prinsip komposisi memperoleh jumlah nilai $=429$ dengan rata-rata $(r)=86$ (baik), prins ip keselarasan memperoleh jumlah nilai $=431$ dengan rata-rata $(r)=86$ (baik), prinsip irama memperoleh jumlah nilai $=427$ dengan rata-rata $(r)=$ 85 , terakhir prins ip keseimbangan memperoleh jumlah nilai $=421$ dengan rata-rata $(r)=84$, dan secara umum nilai keempat prinsip tersebut dikategorikan baik denganjumlah nilai $=341$ dan rata-rata $(\mathrm{r})=$ 85 (baik).
\end{abstract}

Kata Kunci: analis is, gambar hiasan, hijab.

\begin{abstract}
This research is motivated to introduce one of the simple media thatcan be used as a medium in making decorative pictures on the hijab of class X students of SMK Karya Bunda. The limitation of the problem in this studyfocuses on the application of the principles of composition, harmony, rhythm, balance and the level of success in making decorative pictures in hijabX grade students of SMK Karya Bunda. The purpose of this study is to know the application and success rate of the principles of composition, harmony, rhythm, and balance in the making of decorative pictures in the veil of class $X$ students of SMK Karya Bunda. This study uses a qualitative method with a sample of 20 decorative pictures on the veil of class X students of SMK Karya Bunda taken using the Purposive Sampling technique. The data analysis technique was performed by using a qualitative descriptive analysis technique. Based on the data that has been obtained, all the assessment results from the three experts as a whole in the work of decorative drawings on the veil of class X students of SMK Karya Bunda are reviewed based on the principle of composition obtaining a total score $=429$ with an average $(r)=86(\mathrm{good})$, the principle of harmony gets the sum of values $=431$ with an average $(r)=86(\mathrm{good})$, the rhythmprinciple gets the sum of values $=427$ with an average $(r)=85$, finallythe principle ofbalance gets the sum ofvalues $=$ 421 with an average $(r)=84$, and in general the values of the four principles are categorized both with a total score $=341$ and an average $(r)=85(\mathrm{good})$.
\end{abstract}

Keywords: analysis, decorative, hijab

\section{PENDAHULUAN}

Gambar hiasan merupakan salah satu sub bahasan seni rupa. Pada pelajaran gambar hiasan, siswa diperkenalkan berbagai macam media, alat dan bahan untuk dapat menghasilkan karya seni rupa. Pada dasarnya pengetahuan siswa tentang gambar hiasan masih dapat dikatakan umum, sis wahany a mengetahui secara garis besar mengenai materi pembelajaran gambar hiasan. Rendahnya pemahaman siswa mengenai materi gambar hiasan dapat dipeng aruhi oleh berbagai faktor, seperti: kurangnya pengetahuan siswa mengenai gambar hias an, kurangnya kreativitas siswa dalam mengembangkan media dalam menggambar hiasan, dan rendahnya pemahaman siswa mengenai 
objek gambar hiasan, serta rendahnya pengetahuan sis wa terhadap prinsip komposisi, keselarasan, irama, dan keseimbangan pada karya menggambar hiasan. Dari data observasi, penulis mengambil kesimpulan bahwa siswa tidak menerapkan prinsip komposisi, keselaras an, irama, dan kes eimbangan dalamkaryanya sehingga menyebabkan banyak kekurangan dalam karya tersebut. Kekurangan dari prinsip komposisi terdapat pada peletakan motif yang kurang sesuai, warna yang tidak kontras dan motif menyebar luas di bidang kain dengan tidak teratur. Kekurangan dari prinsip keselarasan terdapat pada tidak selarasnya ukuran motif satu dengan motif lainnya, serta tidak teraturnya penempatan motif pada bidang hijab. Selain itu, kekurangan prinsip irama yaitu tidak adanya pengulangan motif pada karya. Dan terakhir, kekurangan prinsip kes eimbangan terletak pada tidak seimbangnya besar kecilnya ukuran motif gambar hias an dan tidak s eimbangnya warna motif satu dengan warna motif lainnya. Karena banyaknya kekurangan membuat tingkat keberhasilan dalam pembuatan karya siswa sangat memperihatinkan. Siswa sering gagal membuat karya yang memuaskan sesuai dengan prinsip-prinsip yang harusnya di terapkan.

Selain itu kenyataannya di lapangan, siswa sering sekali menggambarkan hiasan bertema geometris sebagai hias an. Jika, lebih dikembangkan banyak tema yang dapat digambar oleh sis wa, salah satunya yang lebih sederhana yaitu bertemakan flower (bunga). Media yang digunakan dalammenggambar oleh siswa disekolah kurang variasi. Sis wa selalu menggunakan media kertas dan kanvas. Padahal, jika dikembangkan banyak media lain yang dapat digunakan, s eperti: kayu, sepatu, baju, hijab, dan lain sebaginya. Pada penelitian ini, penulis akan mengembangkan gambar hiasan dengan media hijab bertemakanflower (bunga) sebagai bahan peneltian yang akan diterapkan kepada siswa kelas X SMK Karya Bunda dengan menekankan prins ip komposisi, keselarasan, irama, keseimbangan.

\section{KAJIAN TEORI}

\section{Gambar}

Menggambar, menurut Kamus Besar Bahasa Indonesia (KBBI) versi online, yaitu: Kegiatan meniru barang, orang, binatang, dan sebagainya yang dibuat dengan coretan pensil atau alat lainnya pada sebuah kertas. Akan tetapi, hasil darikegiatan seni yang satu ini tidak hanya soal tiru-meniru suatu obyek. Sebuah gambar dapat menyampaikan apa yang dirasakan oleh sang pembuat gambar. Kita dapat melihat bagaimana kondisi emosi s eseorang lewat gambar yang dibuatnya.
Gorga : Jurnal Seni Rupa

Volume 09 Nomor 01 Januari-Juni 2020

p-ISSN: 2301-5942 | e-ISSN: 2580-2380

Gambar merupakan membuat goresan di suatu bidang menggunakan pensil, arang (charcoal), konte, pena, dan sebagainya. Bidang ini bisa berbentuk dua dimensi seperti kanvas, kertas, kain, ataupun bidang tiga dimensi, seperti bangunan, tubuh, batu, dan lainnya (Maria, Mia dan Belle Bintang Biarezky, 2016 : 30).

Sedangkan menurut Simon, (2003 : 1) menggambar merupakan sesuatu yang erat dan alami, yang ada hubungannya dengan salah satu keinginan manusia. Dengan gambar, manusia ingin mengekspresikan diri, pola pikir, dan emosi-emosinya. Mesra dalam Siregar (2020: 95) mengatakan bahwa menggambar merupakan suatu kegiatan memindahkan bentuk objek ke atas bidang datar atau dua dimensi, capaian yang diharapkan dalamkegiatan ini adalah kemiripan bentuk objek dengan gambar yang dihasilkan.

Berdas arkan pendapat di atas gambar merupakan hasil dari gores an yang mening galkan bekas di atas bidang datar, dengan memiliki makna atau bentuk hasil dari goresan tersebut.

\section{Hiasan atau Ragam Hias}

Mis giya, (2013 : 5) Is tilah ragam hias beras al dari dua perkataan ragamdan hias yang berpadu menjadi satu pengertian pola. Dalam Bahasa Inggris disebut ornament dan dalam Bahasa Belanda dikatakan siermotieven. Ini dapat dilihat pada terjemahan Van Der Hoop di pendahuluan sebagai berikut: "Arti suatu ragam hias tidak gampang diterangkan dengan satu kata, sering arti itu malahan sama sekali tidak tentu.

\section{Hijab}

Secara etimologi, hijab beras al dari bahasa Arab yang kata bendanya berarti penutup, kata das arnya berarti menutupi, melindungi. Hal ini dapat kita lihat pada terjemahan dari: hijab or hijāab (حجاب , IPA: [hi. 'dzæ:b]) is the Arabic word for "curtain / cover" (noun), based on the root حجب meaning "to cover, to veil, to shelter". In popular use, hijab means "head cover and modest dress for women" among Muslims, which most Islamic legal systems define as covering everything except the face, feet and hands in public. Hijab adalah penutup atau kerudung yang dikenakan oleh perempuan mus lim apabila mereka keluar rumah untuk suatu keperluan dan merupakan tolok ukur yang membedakannya dari yang lain. Hijab ini untuk membedakan dia dengan laki-laki dan melindungi pribadi perempuan mus lim pada saat berada di antara lawan jenisnya (Rahayu, 2016: 263).

Hijab merupakan salah satu atribut yang dikenakan oleh wanita muslim. Allah memerintahkan kepada 


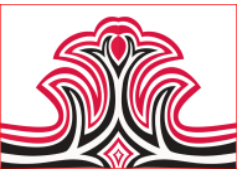

kaum wanita untuk menutup aurat, seperti yang tercantum dalam surah al-Ahzab ayat 59: "Wahai Nabi, katakanlan kepada isterimu dan anak-anak perempuanmu, serta para perempuan mukmin agar mereka mengulurkan jilbabnya. Sebab, yang demikian itu akan membuat mereka lebih mudah dikenali sehingga terhindar dari perlakuan tidak sopan. Sesungguhnya Allah Maha Pengampun dan Maha Penyayang”.

Untuk menjaga aurat perempuan, maka kaum perempuan dianjurkan untuk menutup auratnya dengan berpakaian yang baik atau biasa disebut berhijab. Menggunakan hijab artinya menutup aurat mulai dari rambut hingga bagian dada yang diwajibkan bagi seorang perempuan (Budiyanti, 2017 : 203).

\section{METODE PENELITIAN}

Metode yang digunakan dalam penelitian ini adalah metode kualitatif, dan teknik pengumpulan data yang digunakan adalah participant observation (observasi berperan serta) dan dokumentasi. Ins trumen penelitian, pedoman observasi dan pedoman dokumentasi. Teknik pengumpulan data, dokumentasi dan observasi (pengamatan). Teknik analisis data, teknik analis is data yang digunakan dalam penelitian ini adalah teknik analis is data kualitatif.

\section{HASIL DAN PEMBAHASAN}

\section{Hasil}

Dalam pembuatan gambar hiasan pada hijab siswa kelas X SMK Karya Bunda peneliti menggunakan Prinsip komposisi, keselarasan, keseimbangan, dan irama, serta diperoleh pembobotan nilai berupa angka, untuk selanjutnya akan di deskripsikan. untuk mencapai sebuah estetika visual. Sehingga hasil karya des ain dapat dinikmati dan diapresiasi oleh orang lain .

\section{1). Karya 1}

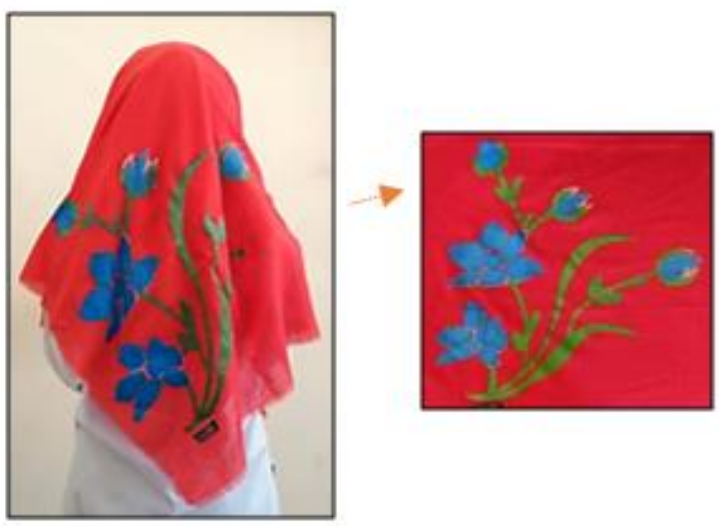

Gambar 1. Karya Apdullah (Sumber: Fazri Bagas Prasojo, 2019)
Gorga : Jurnal Seni Rupa

Volume 09 Nomor 01 Januari-Juni 2020

p-ISSN: 2301-5942 | e-ISSN: 2580-2380

Setelah data dikumpulkan dan dianalis is secara umum maka diketahui bahwa Prinsip komposisi dengan nilai secara umum $=84$ (baik), prinsip kes elarasan dengan nilai secara umum $=86$ (baik), Selanjutnya diikuti dengan Prinsip irama dengan nilai secara umum $=82$ (baik), Prinsip penilaian yang terakhir adalah keseimbangan dengan nilai secara umum $=85$ (baik) jumlah nilai $=337$ dengan rata-rata $(r)=84$ (baik).

\section{2). Karya 2}
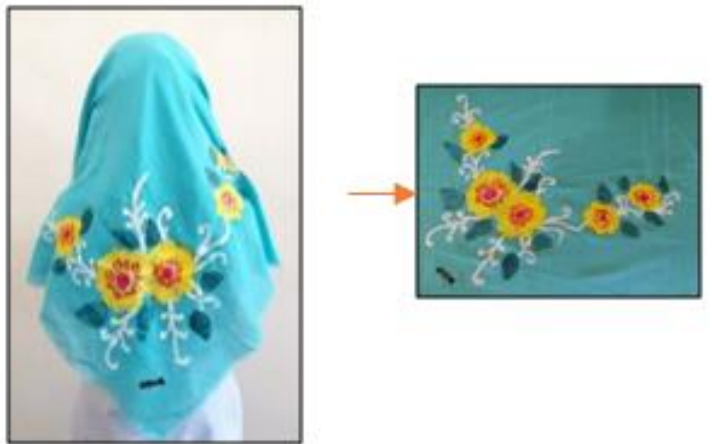

Gambar 2. Karya Abraham (Sumber: Fazri Bagas Prasojo, 2019)

Setelah data dikumpulkan dan dianalis is secara umum maka diketahui bahwa Prinsip komposisi dengan nilai secara umum $=86$ (baik), prinsip kes elarasan dengan nilai secara umum $=87$ (baik), Selanjutnya diikuti dengan Prinsip irama dengan nilai secara umum $=84$ (baik), Prinsip penilaian yang terakhir adalah keseimbangan dengan nilai secara umum $=86$ (baik) jumlah nilai $=343$ dengan rata-rata $(r)=86$ (baik).

\section{3). Karya 3}

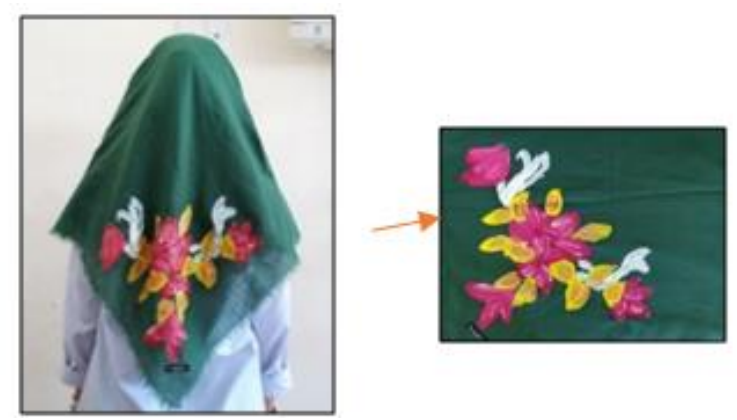

Gambar 3. Karya Asrani (Sumber: Fazri Bagas Prasojo, 2019)

Setelah data dikumpulkan dan dianalis is secara umum maka diketahui bahwa Prinsip komposisi dengan nilai secara umum $=86$ (baik), prinsip keselarasan dengan nilai secara umum $=85$ (baik), Selanjutnya diikuti dengan Prinsip irama dengan nilai secara umum $=85$ (baik), Prinsip penilaian yang terakhir adalah 
kes eimbangan dengan nilai secara umum $=84$ (baik) jumlah nilai $=340$ dengan rata-rata $(r)=85$ (baik).

\section{4). Karya 4}
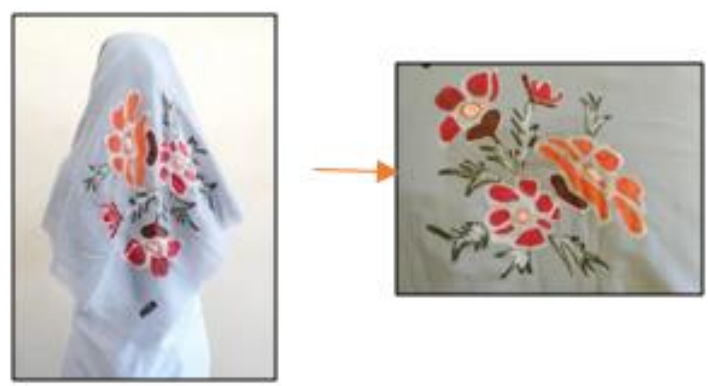

Gambar 4. Karya Markus (Sumber: Fazri Bagas Prasojo, 2019)

Setelah data dikumpulkan dan dianalisis secara umum maka diketahui bahwa Prinsip komposisi dengan nilai secara umum $=86$ (baik), prinsip keselarasan dengan nilai secara umum $=86$ (baik), Selanjutnya diikuti dengan Prinsip irama dengan nilai secara umum $=83$ (baik), Prinsip penilaian yang terakhir adalah keseimbangan dengan nilai secara umum $=85$ (baik) jumlah nilai $=340$ dengan rata-rata $(r)=85$ (baik).

\section{5). Karya 5}

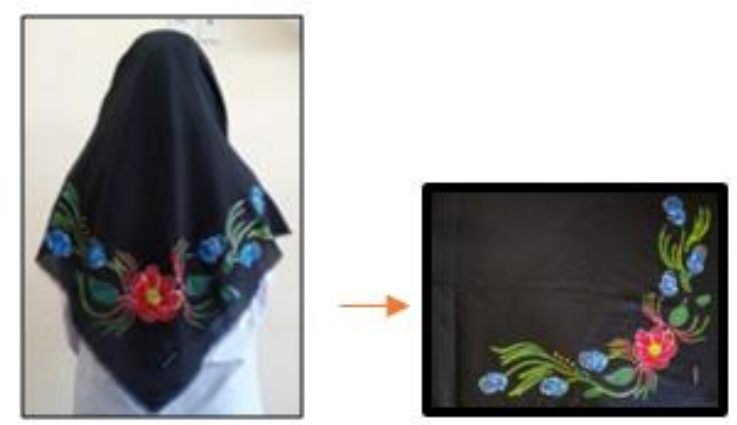

Gambar 5. Karya Raisa

(Sumber: Fazri Bagas Prasojo, 2019)

\section{Pembahasan}

Dalam aplikasi prinsip komposisi, keselarasan, irama, dan keseimbangan pada 5 karya gambar hiasan pada hijab siswa kelas X SMK Karya Bunda, dikategorikan baik dengan jumlah nilai $=341$ dan rata-rata $=85$ (baik). Penilaian yang lebih tinggiterdapat pada Prinsip keselaras an dengan jumlah nilai $=431$ dan nilai ratarata $=86$ (baik), sementara pada Prinsip komposisi dengan jumlah nilai $=429$ dan nilai rata-rata $=86$ (baik), selanjutnya diikuti dengan Prin sip irama jumlah nilai $=427$ dan nilai rata-rata $=85$ (baik), terakhir
Gorga : Jurnal Seni Rupa

Volume 09 Nomor 01 Januari-Juni 2020

p-ISSN: 2301-5942 | e-ISSN: 2580-2380

Prinsip yang terendah adalah keseimbangan dengan jumlah nilai $=421$ dan nilai rata-rata $=84$ (baik).

\section{KESIMPULAN DAN SARAN \\ 1.Kesimpulan}

Berdasarkan data yang telah diambil dari 5 karya gambar hias an pada hijab siswa kelas X SMK Karya Bunda, maka tingkat keberhasilan penerapan prinsip komposisi, keselarasan, irama, dan keseimbangan berdasarkan penilaian tiga orang penilai dikategorikan baik dengan jumlah nilai $=341$ dan rata-rata $=85$ (baik). Penilaian y ang lebih tinggi terdapat pada Prinsip keselarasan dengan jumlah nilai $=431$ dan nilai ratarata $=86$ (baik), sementara pada Prinsip komposisi dengan jumlah nilai $=429$ dan nilai rata-rata $=86$ (baik), s elanjutnya diikuti deng an Prins ip irama jumlah nilai $=427$ dan nilai rata-rata $=85$ (baik), terakhir Prinsip yang terendah adalah keseimbangan dengan jumlah nilai $=421$ dan nilai rata-rata $=84$ (baik).

\section{Saran}

Dalam upaya pengembangan karya gambar hiasan pada hijab siswa kelas X SMK Karya Bunda, maka siswa diharapkan untuk lebih aktif dan berpikir kreativ dalam pelajaran seni budaya khususnya bidang seni rupa supaya meningkatkan hasil belajar, dan siswa diharapkan dapat memahami dan mengerti hal-hal paling penting sebelum membuat karya, seperti memahami unsur dan prinsip seni rupa agar dapat menghasilkan karya gambar hiasan pada hijab yang lebih baik. Bagi guru supaya lebih efektif dalam mengajar, guru diharapkan dapat mengajarkan siswa hal-hal paling penting sebelum menggambar seperti: siswa harus lebih dulu memahami unsur dan prinsip seni rupa agar sis wa lebih aktif dan terampil di dalam pelajaran, serta guru diharapkan agar dapat memantau sis wa dalam setiap proses pembuatan gambar hiasan pada hijab agar meningkatkan kualifitas karya yang dibuat siswa.

\section{DAFTAR RUJUKAN}

Budiyanti, Setia. (2017). Faktor-Faktor Yang Mempengaruhi Pemakaian Jilbab Di Kalangan Mahasiswi Universitas Swadaya Gunung Jati Kota Cirebon. Jurnal. Pendidikan Islam, 08(02), 203212.

(2007). KBBI (Kamus Besar Bahasa Indonesia) Edisi $\mathrm{Ke}-2$, Jakarta : Balai Pustaka Jakarta.

Maria, Mia dan Belle Bintang Biarezky. (2016). Seni Rupa Kita. Jakarta: Gajah Hidup Printing.

Mis giya. (2013). Ornamen.. Medan: FBS.UNIMED.

Siregar, N. H., Azis, A. C. K., Mesra, M., \& Mirwa, T. (2020). Analisis Gambar Bentuk Bunga Anggrek 
dengan Teknik Pointilis Berwarna di SMP AlFityan School Medan. Gorga: Jurnal Seni Rupa, 9(1), 94-99.

Simon, Howard. (2003). Teknik Menggambar. Semarang: Effhar.

Rahayu, Titik dan Siti Fathonah. (2016). Tubuh Dan Jilbab:Antara Diri Dan 'Liyan'. Jurnal.Pemikiran Islam Dan Filsafat, 13(02), 263-282. 